\title{
Impacts of organic coagulant aid on purification performance and membrane fouling of coagulation/ultrafiltration hybrid process with different Al-based coagulants
}

\author{
Weiying $\mathrm{Xu}{ }^{\mathrm{a}, \mathrm{b}, *}$, Qinyan Yue ${ }^{\mathrm{c}, * *}$, Baoyu Gao ${ }^{\mathrm{c}}, \mathrm{Bin} \mathrm{Du}{ }^{\mathrm{a}}$ \\ ${ }^{a}$ Key Laboratory of Chemical Sensing \& Analysis in Universities of Shandong, School of Resources and Environmental Sciences, University of Jinan, Ji' nan 250022, Shandong, People's Republic of China \\ ${ }^{b}$ State Key Laboratory of Environmental Aquatic Chemistry, Research Center for Eco-Environmental Sciences, Chinese Academy of Sciences, Beijing 100085, China \\ c Shandong Key Laboratory of Water Pollution Control and Resource Reuse, School of Environmental Science and Engineering, Shandong University, Ji' nan 250100, Shandong, People's Republic of China
}

\section{H I G H L I G H T S}

- PD aid in alum and PACl coagulations could improve HA removal by C-UF process.

- Floc size had more important effect on UF than compact degree.

- PD-alum/PD-PACl led to the highest fluxes but was most susceptible to high shear.

- $R_{c}$ and $R_{a}$ were chiefly affected by floc size and $D_{f}$, respectively.

\section{G R A P H I C A L A B S T R A C T}

Resistance analyses of the investigated systems: coagulations by different alum-based and PACl-based coagulants with and without floc breakage and re-growth phases.
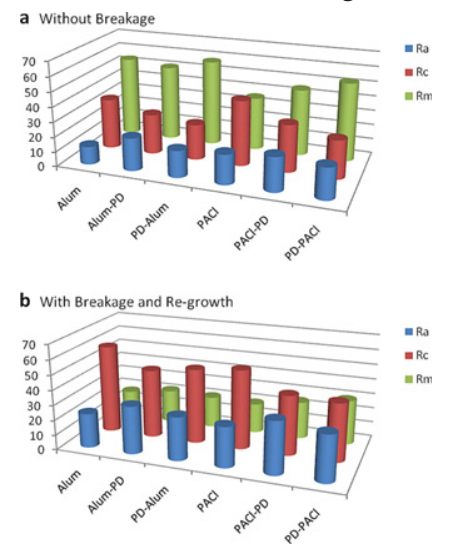

\begin{abstract}
A B S T R A C T
Effects of polydimethyldiallylammonium chloride (PD) on coagulation behaviors of different Al-based coagulants were investigated in coagulation-ultrafiltration (C-UF) hybrid process, regarding the impurity removal efficiency, floc properties and membrane foulings. Floc characteristics, including floc size, compact degree, strength and re-growth ability were studied using a laser diffraction particle sizing device. Resistance analyses were implemented to explore the membrane fouling mechanisms. The results indicated that PD aid could increase the purification efficiency of C-UF, especially at low coagulant doses. PD-alum/PD-PACl contributed to large flocs, while alum-PD/PACl-PD gave rise to flocs with high $R_{f}$ and $D_{f}$ values. The results of ultrafiltration experiments showed that conventional coagulant, i.e., alum led to a flux reduction of $52 \%$; while the reductions for alumPD and PD-alum were 53\% and 34\%, respectively. The flux reductions for PACl, PACl-PD and PD-PACl were $60 \%, 57 \%$ and $39 \%$. Flux declines became more severe when the coagulated suspensions were exposed to increased shears and the suspensions coagulated by aluminum plus PD resulted in the least reductions in fluxes.
\end{abstract}

(c) 2014 Elsevier B.V. All rights reserved.

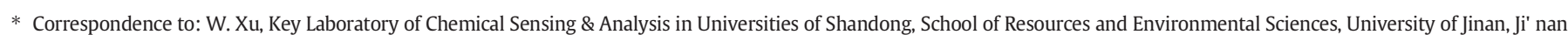
250022, Shandong, People's Republic of China.

** Corresponding author.

E-mail addresses: stu_xuwy@ujn.edu.cn (W.Xu), qyyue@sdu.edu.cn (Q. Yue).
} 


\section{Introduction}

Low pressure driven membrane filtration, ultrafiltration (UF), has been receiving a lot of attention and is now increasingly used as a technology for surface water purification. UF can effectively remove particles, turbidity, microorganisms (bacteria, protozoa, algae), and some viruses. Nevertheless, the main drawback of this technology is membrane fouling, which is a major obstacle to the widespread application in water and wastewater treatment of UF throughout the world. Generally, the accumulation of the retained matter on the membrane surface leads to an increase in operating costs, due to increased energy consumption and the necessity of periodic cleaning. Up to now, numerous researchers have studied membrane foulants for many types of membranes with various feed waters and they concluded that most of the natural organic matter (NOM) components are major membrane foulants [1-3]. Humic acid (HA), as the main component of NOM, is considered to be closely associated with membrane fouling [4,5]. Using pretreatment to lower the NOM concentration of feedstock has been a useful approach to prevent membrane fouling.

Chemical coagulation could significantly enhance the performance of UF in water treatment. Indeed, it is now a common practice to add coagulants into feed water to improve the NOM removal and filtration flux of ultrafiltration unit [6,7]. Our previous study [8] employed various Albased coagulants in C-UF process and the results revealed that the membrane permeate fluxes varied for different coagulants. That was essentially induced by the distinct properties of aggregates formed by different coagulants in the coagulation/flocculation processes. Actually, there is a great amount of literatures supporting the importance of floc properties in C-UF and/or C-MF (coagulation-microfiltration) hybrid processes. Hwang and Liu [9] reported that effective conventional coagulation conditions generally produced larger particles and this reduced membrane fouling by reducing adsorption in membrane pores, increasing cake porosity and transport of foulants away from the membrane surface. Cho et al. [10] suggested that coagulated flocs with lower fractal dimension could improve membrane permeability due to their higher porosity and relative loose aggregation. Barbot et al. [11] found that the effect of coagulation system on the permeate flux depended on the ability of floc resistance to shear stress. Large flocs, which were highly resistant to shear, led to a $20 \%$ increase in permeate flux because they were not easily broken; while large flocs but with weaker resistant to shear resulted in a decrease of $50 \%$ in permeate flux. The results of our previous research [12] proved that flocs formed by pre-hydrolyzed $\mathrm{Al}$ coagulants, such as $\mathrm{PACl}$, were stronger than those by conventional alum. However, they commonly had more compact structures and hence, pre-hydrolyzed $\mathrm{Al}$ species could not essentially improve the permeate flux despite of its superior coagulation behaviors.

Organic polymeric coagulants, like polydimethyldiallylammonium chloride (PDMDAAC or PD for short), have been used in water purification for several decades. Many researchers have considered using PDMDAAC in drinking water treatment due to its wider working $\mathrm{pH}$ range and lower dosage demand than metal coagulants for equivalent treatment efficiency $[13,14]$. However, the high cost of PDMDAAC limits its comprehensive application in water treatment and thus it was generally used in combination with metal coagulants [15]. In this circumstance, PD was used as primary coagulant aid of two different aluminum coagulants, a commercial product (alum) and lab-prepared material (polyaluminum chloride, i.e., $\mathrm{PACl}$ ), expecting to obtain superior aggregates propitious to the ultrafiltration performance. This has rarely been reported and could have great practical significance.

Besides, various mixing modes were implemented in the coagulation process to explore the effect of increased shear on floc properties and membrane foulings. In natural as well as technical aquatic systems particles and flocs in suspension undergo highly different and varying flow conditions, which are always accompanied by various shear forces. In C-UF system, the circulation of suspension also commonly induces variation of shear stress. Depending on the binding strength of the particles or aggregates, the action of shear forces may lead to deformation and eventual floc break-up. Over the last three decades, numerous studies have been carried out to obtain information on the particle characteristics under certain hydraulic shear and to bring considerable insight into the mechanisms involved in floc formation and break-up. However, most of the previous studies focused on the relationship between shear conditions and floc properties, while the effect of different shear conditions on the subsequent membrane performances remains unclear, which is necessary and of significant meaning.

The present paper was thus focused on (1) the influences of PDADMAC aid on floc properties and ultrafiltration performances for different Al coagulants in C-UF processes; (2) floc properties and membrane behaviors for the coagulants with PD aids when the pre-formed flocs were exposed to enhanced shear rates; and (3) comparison of membrane fouling mechanisms by coagulation effluents with and without PD aids.

\section{Materials and methods}

\subsection{Humic acid solution and coagulant preparations}

The biochemical reagent HA was purchased from the Jufeng Chemical Technology Co. Ltd., Shanghai, China. HA sample water with the concentration of $10.0 \mathrm{mg} / \mathrm{L}$ was prepared as previously described [8].

Two Al-coagulants, alum and $\mathrm{PACl}$ with a basicity value $(\mathrm{B}, \mathrm{OH} / \mathrm{Al}$ molar ratio) of 2.2 were used in this study and the preparation details can be found in other paper [16,17]. Cationic polymer PDMDAAC (40\% $\mathrm{w} / \mathrm{w}$ aqueous solution, $100 \%$ charge density) was purchased from Bin Zhou Chemical Co., Shandong, China and its intrinsic viscosity was $1.02 \mathrm{dL} / \mathrm{g}$. PD solution with a target concentration of $1.0 \mathrm{~g} / \mathrm{L}$ was prepared by dissolving pre-determined PD into DI water under continuous stirring.

\subsection{Pre-coagulation-ultrafiltration (C-UF) experiments}

Jar tests were carried out using a programmable jar test apparatus (ZR4-6, Zhongrun Water Industry Technology Development Co. Ltd., China) composed of six $1.0 \mathrm{~L}$ cylindrical plexiglass beakers. HA water samples were first stirred at 200 revolutions per minute (rpm) for 30 $s$ with the purpose of uniform mixing, and then the prepared coagulants were added. PD aid was added in two ways. For the first one, Al coagulant was dosed firstly at the start of rapid mixing period, followed by PD addition after $30 \mathrm{~s}$, and then the rapid mixing continued for another $1 \mathrm{~min}$. This dual-coagulant was referred as alum-PD/PACl-PD. For the second one, referred as PD-alum/PD-PACl, the addition sequence of $\mathrm{Al}$ and PD coagulants was reversed. After the rapid mixing stage, 15 min of slow stirring period at $40 \mathrm{rpm}$ was introduced to allow floc growth. Zeta potentials (ZP) were measured a few seconds after coagulant addition using a Zetasizer $3000 \mathrm{HSa}$ (Malvern Instruments, UK). A dead-end batch UF unit was set up to filter the coagulated water as shown in Fig. 1. Commercial polyethersulfone (PES) flat membrane (Mosu Co. Ltd., China) was used throughout the experiments and the characteristic parameters of the membrane were listed in Table 1. Nitrogen gas was used to maintain precise supply of constant pressure at $220 \mathrm{kPa}$. For more detailed procedures of the C-UF process, please refer to the literature [8].

\subsection{Floc characterizations}

\subsubsection{On-line measurement of floc size}

A laser diffraction instrument (Mastersizer 2000, Malvern, UK) was used to continuously measure the dynamic floc size as the coagulation proceeded and the details have been reported in other paper [18].

\subsubsection{Floc strength, recovery ability and structure analyses}

A series of jar tests with 5 min of breakage periods at $200 \mathrm{rpm}$, performed after the floc had reached their steady stage, were conducted to 


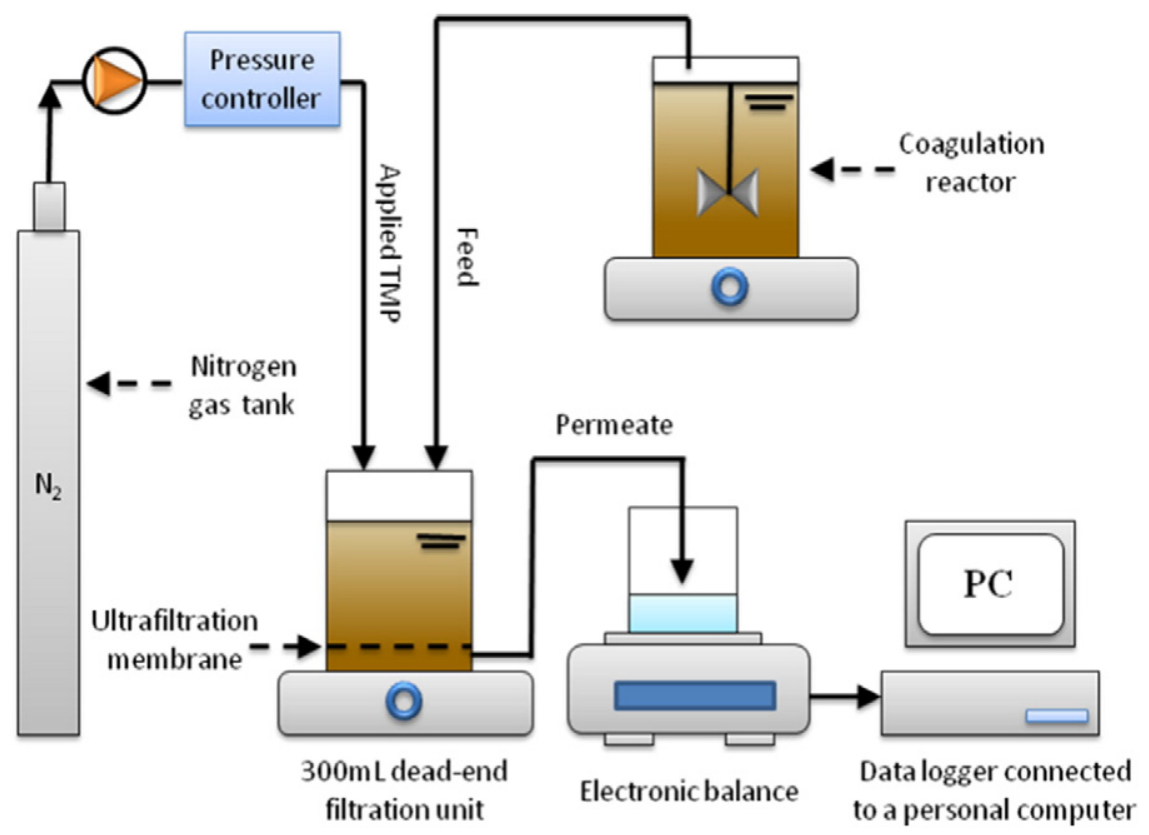

Fig. 1. Schematic diagram of coagulation-ultrafiltration (C-UF) hybrid process.

investigate the floc strength and recovery abilities. After breakage, slow mixing at $40 \mathrm{rpm}$ was reintroduced for anther $15 \mathrm{~min}$ to allow the floc re-formation. The relative breakage and re-growth of different flocculated systems have previously been expressed by use of floc strength and recovery factors $[19,20]$ which may be calculated as follows:

Strength factor $\left(S_{f}\right)=\frac{d_{2}}{d_{1}} \times 100$

Recovery factor $\left(R_{f}\right)=\frac{d_{3}-d_{2}}{d_{1}-d_{2}} \times 100$

where $d_{1}$ is the floc size of the plateau before breakage, $d_{2}$ is the floc size after breakage, and $d_{3}$ is the floc size after re-growth to the new plateau.

Flocs are examples of mass fractal objects as both the internal and surface structures of the aggregate exhibit fractal properties. In this study, small-angle laser light scattering (SALLS) was used to determine the $D_{f}$ of flocs formed in coagulation unit, which could be described by the following relationship between the total scattered light intensity $I$ and the scattering vector $Q$ by $D_{f}[21,22]$ :

$I \propto Q^{-D_{\mathrm{f}}}$

$Q$ is the difference between the incident and scattered wave vectors of the radiation beam in the medium [21], which is given by:

$Q=\frac{4 \pi n \sin (\theta / 2)}{\lambda}$

where $n, \theta$ and $\lambda$ is the refractive index of the suspending medium, the scattering angle and the wavelength of the radiation in a vacuum, respectively. According to Eq. (3), $D_{f}$ could obtained by plotting $I$ against

Table 1

Characteristic parameters of PES membrane.

\begin{tabular}{ll}
\hline Characteristic parameters & Values \\
\hline Cut-off molecular weight $(\mathrm{MWCO}) / \mathrm{kDa}$ & 100 \\
Mean pore size $\left(r_{\mathrm{mp}}\right) / \mathrm{nm}$ & 5.74 \\
Zeta potential $/ \mathrm{mV}$ & $-2.2 \pm 0.05$ \\
Hydraulic permeability $/ \times 10^{-10} \mathrm{~m}^{3} / \mathrm{m}^{2}$ Pa s & $10.03 \pm 0.58$ \\
\hline
\end{tabular}

Q on a log-log scale. If there is a straight line, the power law relationship exists and the slope of the line indicates the $D_{f}$ value.

\subsection{Resistance analyses}

For the dead-end membrane filtration, the permeate flux $(J)$ can be expressed as [23]

$J=\frac{\Delta P}{\mu R_{t}}=\frac{\Delta P}{\mu\left(R_{m}+R_{c}+R_{a}+R_{p}\right)}$

where $\Delta P$ is the transmembrane pressure (TMP), $\mu$ is the viscosity of permeate, $R_{t}$ is the total resistance, $R_{m}, R_{c}, R_{a}$ and $R_{p}$ are the membrane resistance, cake resistance, adsorption resistance and pore blocking resistance, respectively.

In this study, a series of tests were performed to determine the different resistances. $R_{m}$ was first determined by filtering DI water through a virgin membrane for at least $2 \mathrm{~h}$ to obtain flux $J_{0}$. Then the same membrane was immersed in the feed water with slow stirring for at least $18 \mathrm{~h}$, which allows the adsorption of foulants on the membrane surface, afterwards DI water was filtered through the "fouled" membrane for another $2 \mathrm{~h}$ to obtain $J^{\prime}$. After this step, the feed water was filtered through the same membrane for $3 \mathrm{~h}$ to get $J$ and the fouled membrane was gently wiped with Kimwipes to remove the cake layer on its surface, and then DI water was filtered once again through the membrane for at least $2 \mathrm{~h}$ to get $J^{\prime \prime}$. Based on the experiments above, the $R_{m}, R_{a}, R_{p}$ and $R_{c}$ can be calculated using Eqs. (6)-(10):

$R_{m}=\frac{\Delta P}{\mu J_{0}}$

$R_{a}=\frac{\Delta P}{\eta J^{\prime}}-R_{m}$

$R_{t}=\frac{\Delta P}{\eta J}$

$R_{p}=\frac{\Delta P}{\eta J^{\prime \prime}}-R_{m}-R_{a}$ 
$R_{c}=R_{t}-R_{m}-R_{a}-R_{p}$

\section{Results and discussion}

\subsection{Effect of coagulant dosage on humic acid removal}

Humic acid solutions were coagulated by alum and PACl (1.0$6.0 \mathrm{mg} / \mathrm{L}$ as $\mathrm{Al}$ ) with PD aid and then the coagulation effluents were filtered through UF membranes. HA removal efficiencies with different coagulants were shown in Fig. 2. A common trend in all the cases was that the HA removal increased gradually with the aluminum concentration at low dosage and at the dose above $4.0 \mathrm{mg} / \mathrm{L}$, the growth trend turned out to be less noticeable. PD aid could augment the HA removals in varying degrees depending on the dosages of aluminum and PD as well as their dosing sequence. It could be observed in Fig. 2(a) that at low alum dosage of 1.0 and $2.0 \mathrm{mg} / \mathrm{L}$, the HA removal rate was around 50 and $60 \%$, respectively. Alum-PD with the PD concentration of $0.5 \mathrm{mg} / \mathrm{L}$ contributed to the most significant increase in HA removal efficiencies, with additional $20-22 \%$. That could be attributed to the better charge neutralization ability of PD, which could destabilize the HA molecules and form fine particles even at low alum dose. And then, the formed aggregates could easily be removed by the ultrafiltration. This was consistent with the previous research by Bolto et al. [24], who found that better coagulation performance was achieved when conventional metal coagulants were used in combination with a polymer. As the alum dosage increased to $3.0 \mathrm{mg} / \mathrm{L}, \mathrm{PD}$ aid could just increase the HA removal by 10 $13 \%$ and at the aluminum dose of $4.0 \mathrm{mg} / \mathrm{L}$ and above, the effects of PD were much slighter. In comparison with alum-PD, PD-alum gave rise to less improvement in HA removal at the same coagulant dose except when the concentration of PD aid was $1.0 \mathrm{mg} / \mathrm{L}$.

The synergistic effect of $\mathrm{PACl}$ and $\mathrm{PD}$ was obviously less significant than that achieved by alum plus PD, especially for the cases at low aluminum coagulant doses (1.0-3.0 mg/L) as shown in Fig. 2(b). It was speculated that the pre-hydrolyzed $\mathrm{PACl}$ was more stable than alum and the various aluminum hydrolysates could work instantaneously after they were added into the suspensions. Better charge neutralization of $\mathrm{PACl}$ provided another benefit to the formation of initial flocs even at quite low concentrations. Therefore, the positive role of PD in the $\mathrm{PACl}$ coagulation system seemed to be less notable than that in alum coagulation system. Still, it could be clearly seen in Fig. 2(b) that, PACl-PD dual coagulant with $0.5 \mathrm{mg} / \mathrm{L}$ PD resulted in the most effective HA removal in comparison with $\mathrm{PACl}$ and $\mathrm{PD}-\mathrm{PACl}$ coagulants.

The variations of zeta potential (ZP) against coagulant dosages were shown in Fig. 3. At the same concentration, PD addition after aluminum led to the largest zeta potential, followed by that when PD was dosed first and single alum/PACl led to the lowest zeta potential. This indicated that PD aid could evidently increase the charge neutralization abilities of

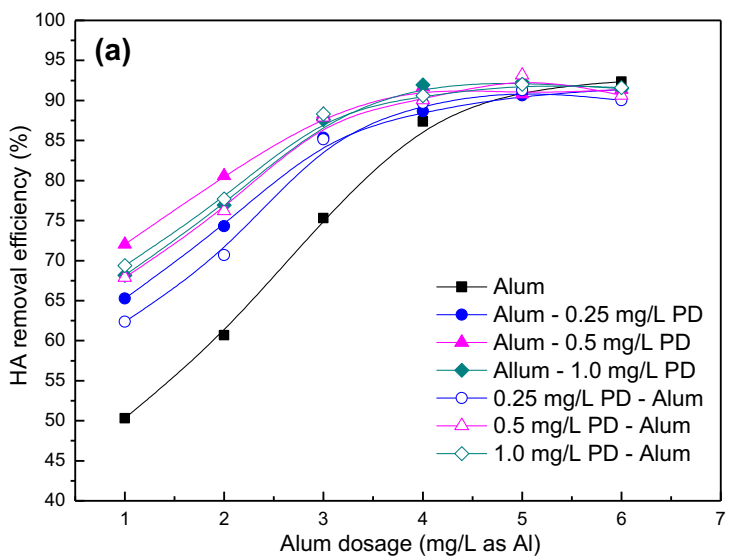

Al-based coagulants regardless of the dosing sequence. This was in agreement with the viewpoint proposed by Kam and Gregory [25] who found that when cationic polymers were used as the coagulant, removal of humic substances from water by coagulation was crucially dependent on neutralization of negative charge. For all the systems with PD aids, zeta potentials increased continuously with the PD concentrations. It was noteworthy to observe that in several cases, zeta potentials reached the isoelectric points as the aluminum doses increased, where charge reversals occurred. Yet, the HA removal did not decrease but kept at high efficiencies as shown in Fig. 2. Pefferkorm [26] pointed out that if the charge neutralization was the only mechanism involved in coagulation, the zeta potential should be in excellent correlation with the coagulation behavior and the optimal removal efficiency was achieved when zeta potential was close to zero. The results obtained in this study implied that charge neutralization seemed to be a crucial, but not exclusive factor influencing the purification behaviors of C-UF.

\subsection{Floc size and structure analyses}

Floc properties were fully explored at the aluminum and PD doses of 3.0 and $0.5 \mathrm{mg} / \mathrm{L}$, respectively. The growth profiles of flocs were monitored as shown in Fig. 4. It could be found that initially, flocs grew rapidly after the coagulant addition and then the growth became slow and finally approached a steady state, where a balance between floc formation and breakage was reached [27,28]. PD aid was observed to have obvious effects on the sizes of flocs. Briefly, the floc sizes followed the order of alum/PACl $<$ alum-PD/PACl-PD $<$ PD-alum/PD-PACl. That could be traditionally explained in terms of different coagulation mechanisms of the dual coagulants. When Al coagulant was dosed firstly under the neutral $\mathrm{pH}$, microflocs were generated in the initial stage of rapid mixing, mainly through $\mathrm{HA}$ adsorption onto aluminum hydroxide or complex reaction to form negatively charged $\mathrm{Al}(\mathrm{OH})_{x}^{3-x}-\mathrm{HA} \mathrm{com-}$ plex [29]. After the high positive charged PD was dosed, it quickly adsorbed on the surfaces of the microflocs and neutralized the negative charges on them effectively, which facilitated the formation of large aggregates. When PD was dosed firstly, the negative charges of HA molecules were more fully neutralized by PD, and the microflocs and colloids formed in the rapid mixing stage could aggregate easily due to the weak repulsion between each other. When alum/PACl was added, freshly formed amorphous precipitates could further enhance the floc growth by adsorption and entrapment. Based on the results provided in Fig. 4, which demonstrated that PD-alum/PD-PACl contributed to apparently larger flocs than alum-PD/PACl-PD, it could be concluded that the adsorption and entrapment of rapidly-formed amorphous precipitates played a more significant role in the aggregate growth than the charge neutralization of PD. Whereas the pre-hydrolyzed $\mathrm{Al}$ species in $\mathrm{PACl}$, such as polynuclear species $\left(\mathrm{Al}_{\mathrm{b}}\right)$, were quite stable and only slowly converted to other forms. This was in marked contrast to the

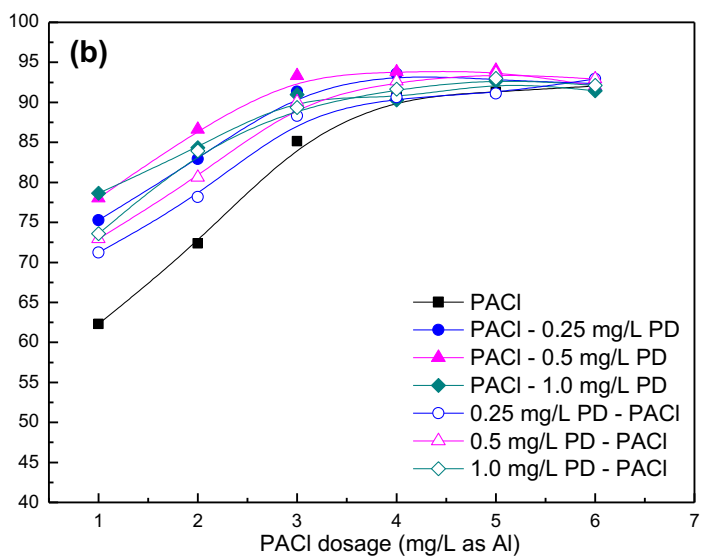

Fig. 2. Removals of HA by coagulation-ultrafiltration hybrid processes with different coagulants and dosages. 

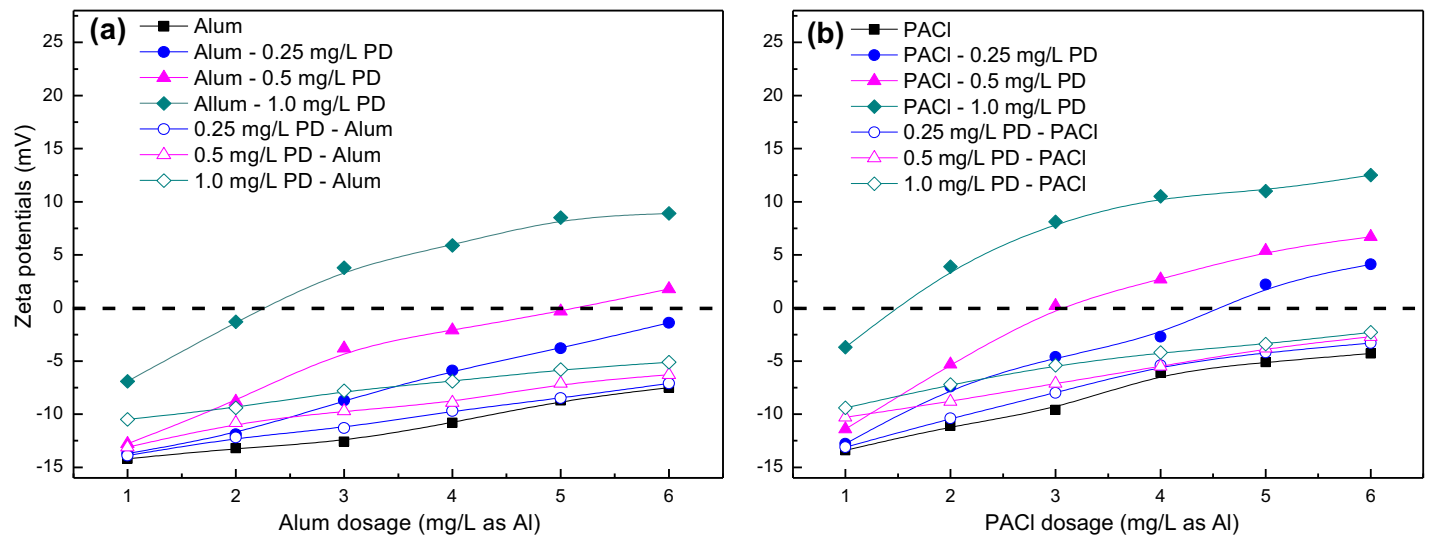

Fig. 3. Variations of zeta potentials with respect to different coagulant types and dosages.

monomeric hydrolysis products in alum, and hence, $\mathrm{PACl}$ present limited adsorption and entrapment effects. This was the possible reason why alum produced larger aggregates than $\mathrm{PACl}$ as illustrated in Fig. 4(a) and (b). Accordingly, PD aid exhibited more prominent effects on improving aggregate sizes in the case of PACl. However, the precise mechanisms have been the subject of much debate and there is a rather extensive and confusing literature on the topic, which needs more in-depth research.
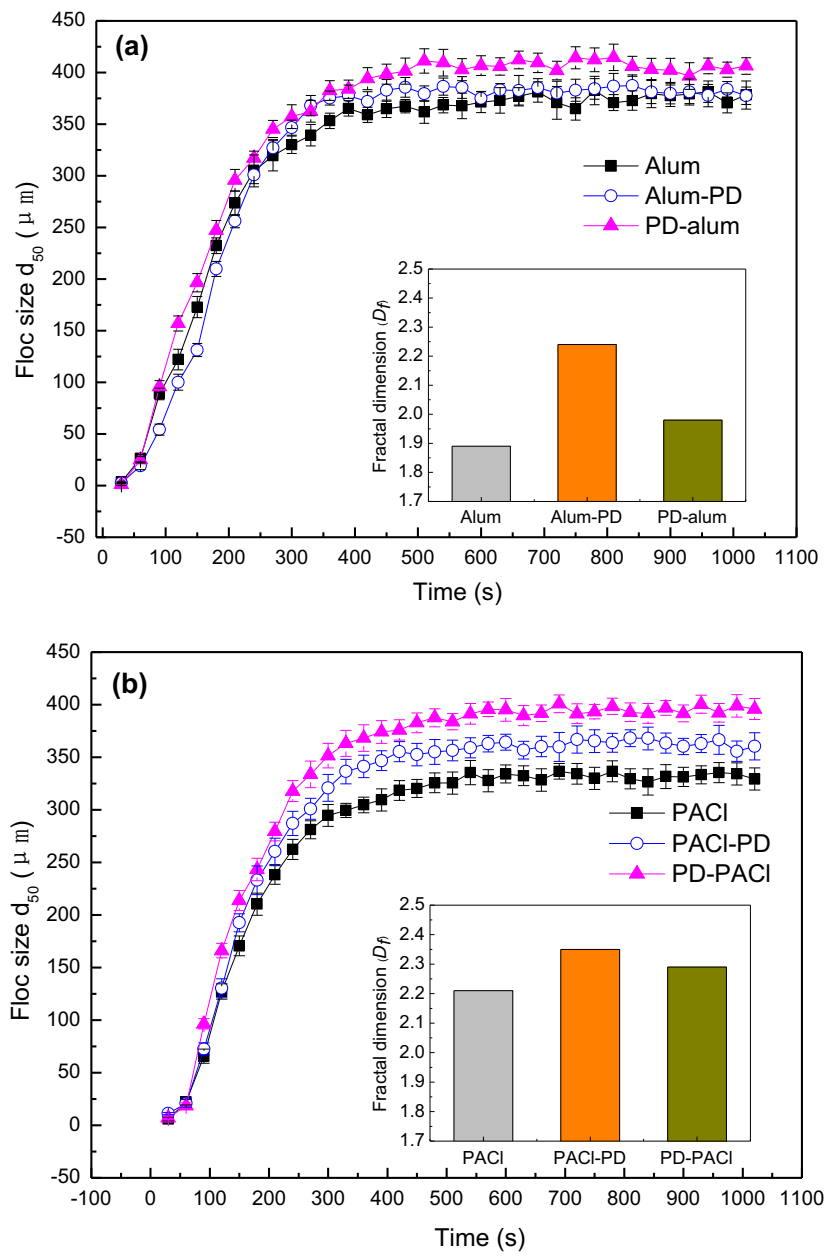

Fig. 4. Variations of floc sizes $\left(d_{50}\right)$ with coagulation time and floc fractal dimensions $\left(D_{f}\right)$ at the steady phases in different coagulation systems at the alum/PACl dose of $3.0 \mathrm{mg} / \mathrm{L}$ as $\mathrm{Al}$ and $\mathrm{PD}$ dose of $0.5 \mathrm{mg} / \mathrm{L}$.
Floc fractal dimension, which is closely related to aggregate structure, was measured when floc growth had reached the plateau and the results were provided in Fig. 4. It could be seen that alum gave rise to flocs with the most open structure with the $D_{f}$ value of 1.89 . Comparatively, aggregates formed by $\mathrm{PACl}$ present more compact structure with higher $D_{f}$ value of 2.21. PD could enhance the charge neutralization mechanism and consequently increase the floc compact degree, and this effect was found to be more pronounced in the case of alum. Besides, the aggregates had obviously larger $D_{f}$ when PD was dosed after aluminum than when PD was added first. That could also be attributed to the excellent charge neutralization ability of alum-PD/PACl-PD as shown in Fig. 3. Furthermore, the hydroxide precipitates formed by the freshly added aluminum coagulants conventionally led to loosely structured aggregates and this was consistent with the conclusion obtained in previous research by $\mathrm{Wu}$ et al. [21], which stated that the absorption, entrapment of contaminants by $\mathrm{Al}$ hydrolyzates resulted in fluffy floc structures.

\subsection{Membrane filtration}

Coagulated suspensions by different coagulants were subjected to a dead-end UF process (Section 2.2) and the normalized permeate fluxes $\left(J / J_{0}\right)$ versus filtration time were shown in Fig. 5 . It could be observed that for all the cases, the permeate fluxes decreased quickly first and then the reduction became gentle with filtration time. That was probably because during filtration, particles larger than membrane pore transported to the membrane surface by drag force (convective force) and adsorbed on the surface through molecular attraction (van der Waals or London forces) [30] and led to formation of cake deposition of flocculants and/or aluminum hydroxide precipitates on the membrane surface. The cake layer acts as a filter media, reducing the effective MWCO of the UF membrane, and consequently resulted in flux declines. As the filtration proceeded, more fine colloids and DOMs adsorbed and plugged into the cake layer pore structures, resulting in a continuous increase of the membrane resistance and flux decrease until the cake layer reached a steady dense state. Filtration was terminated when a constant flux was obtained for each test. The combinations of PD with Al coagulants were found to have significant impacts on flux declines. Specifically, the fluxes by PD-alum/PD-PACl were obviously larger than those by single aluminum and dual coagulants with PD dosed lastly, owing to the different effects of PD on floc characteristics. The properties of flocs, including size and structure, have been proved to have remarked influences on membrane foulings [31,32]. Particle diameter is inversely proportional to specific cake resistance as stated in the well-known Carman-Kozeny equations [32]. According to the results shown in Fig. 4, the steady sizes of aggregates formed in alum and PACl coagulation systems were around 380 and $330 \mu \mathrm{m}$, respectively; while PDalum and PD-PACl gave rise to flocs with sizes of approximately 410 

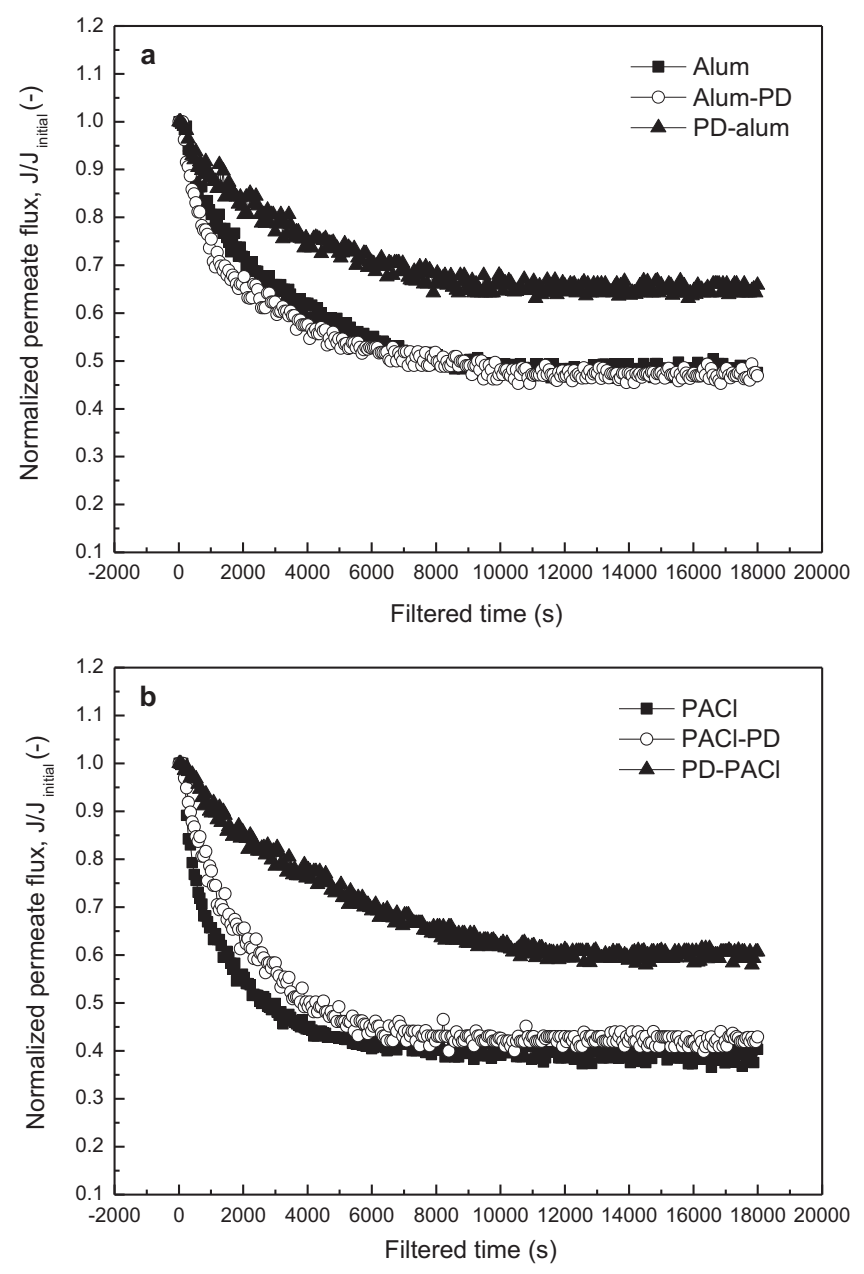

Fig. 5. Normalized UF permeate flux profiles of pre-coagulated suspensions by (a) alum with and without PD aid and (b) PACl with and without PD aid. Dosages of Al-based coagulant and PD aid were fixed at $3.0 \mathrm{mg} / \mathrm{L}$ as $\mathrm{Al}$ and $0.5 \mathrm{mg} / \mathrm{L}$, respectively.

and $400 \mu \mathrm{m}$. Consequently, the cake resistances were decreased and flux declines could be greatly alleviated.

Compact degree of aggregates is another important factor influencing the filtration behaviors. Loosely structured flocs produce less resistance for membrane filtration, while compact flocs lead to cohesively structured cake layer with poor porosity and permeability and thus have adverse effect on membrane permeability [33]. It was noted from Fig. 4 that the PD aid inclined to increase the $D_{f}$ values of flocs, which were supposed to be detrimental to the UF process. Thus, the flux declines for PD-alum/PD-PACl should be more severe than those for sole aluminum salts in this respect. Nevertheless, the data in Fig. 5 were diametrically contrary to the indication of $D_{f}$ values. It can be consequently inferred that floc size played a more significant effect on UF unit than their compact degree. Compared with PD-alum/PD-PACl, PD dosed after aluminum contributed to smaller, more compact aggregates and thus led to more serious flux declines. It was worth noting that the negatively charged membrane in this study was expected to alleviate the membrane fouling through electrostatic exclusion [34,35], especially when the flocs were much negatively charged. However, based on the data shown in Figs. 3 and 5, the fluxes did not follow the same consequence with that of flocs zeta potentials in different coagulation systems. That was possibly because there were other kinds of interactions occurring between the flocs and membrane surface besides electrostatic interaction, such as physical and chemical interactions. Once the cake layer was formed on the membrane surface, the properties of cake layer, which were closely related to the floc characteristics, would become the vital factor influencing fluxes. However, fouling due to dissolved NOM- membrane interaction was not well described and is not yet well understood, though there are many reports that it is generally controlled by charge interaction and adsorptive behavior.

\subsection{Effect of increased shear on floc properties and membrane filtration}

Coagulations with breakage periods were performed to investigate the effect of high shear on UF performance. Floc breaking and reformation phases were conducted as mentioned in Section 2.3.2. The final suspensions were used as the feed water for UF tests and the associated normalized permeate fluxes with filtration time were plotted in Fig. 6. Floc characteristics during breakage and re-growth stages were monitored online and several parameters of floc properties, including floc mean sizes $\left(d_{50}\right)$ under different coagulation stages, strength and recovery factors $\left(S_{f}\right.$ and $\left.R_{f}\right)$ and fractal dimension $\left(D_{f}\right)$, were investigated and furnished in Table 2. It was obvious that high shear led to notable size decrease. Although the broken flocs were allowed to re-grow in the following slow stirring stage, the data $\left(d_{3}\right)$ listed in Table 2 proved that the broken aggregates could never regrow to their original sizes. The flux declines were more severe with breaking phases as shown in Fig. 6 compared with the data in Fig. 5, owing to the inverse relationship between particle size and cake resistance. Besides, high shear gave rise to aggregates with higher $D_{f}$, i.e. more compact structures, which could also augment the UF resistance and aggravate the flux declines.
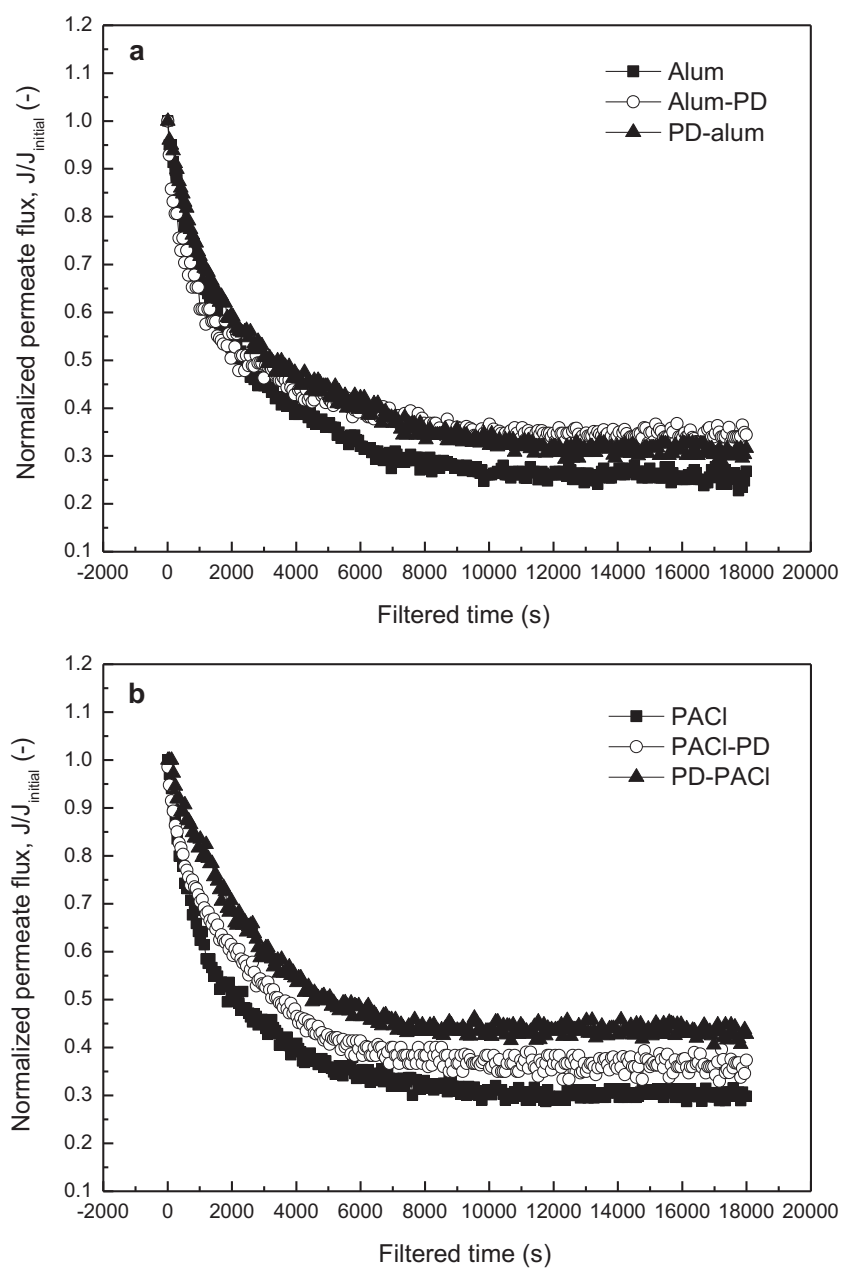

Fig. 6. Normalized UF permeate flux profiles of pre-coagulated suspensions by (a) alum with and without PD aid and (b) PACl with and without PD aid with breakage and regrowth stages. Dosages of Al-based coagulant and PD aid were fixed at $3.0 \mathrm{mg} / \mathrm{L}$ as $\mathrm{Al}$ and $0.5 \mathrm{mg} / \mathrm{L}$, respectively. 
Alum-PD/PACl-PD resulted in the slightest flux decline changes, meaning that $\mathrm{PD}$ addition after aluminum facilitated the construction of a more stable C-UF hybrid process. This could be interpreted from the perspective of property changes of flocs formed by various coagulants after breakage and re-growth. PD aid could definitely increase the $R_{f}$ values of flocs for both alum and PACl (Table 2), which accordingly could increase the final floc sizes after re-growth. When PD was added after aluminum salts, broken flocs present the best re-growth abilities with the largest $R_{f}$ values. That was due to the high charge neutralization of PD, which eliminated the repulsive forces between the broken floc fragments and facilitated their re-aggregation. Yet, alum$\mathrm{PD} / \mathrm{PACl}-\mathrm{PD}$ gave rise to the flocs with the largest $D_{f}$ after re-growth, which resulted in the most dense cake layer with largest resistance. Still, based on the above mentioned discussions, stating that fluxes in the UF units were majorly depended on the floc size instead of $D_{f}$ value, alum-PD/PACl-PD was supposed to build C-UF with least fluctuations in fluxes when exposed to enhanced shears. This was consistent with the results shown in Figs. 5 and 6. However, it should be noted that fluxes for PD-alum/PD-PACl presented the greatest reductions when exposed to the enhanced shears in spite of the high $R_{f}$ of flocs. That was due to the poor strength of flocs formed in the systems, indicated by the low $S_{f}$ values shown in Table 2 . The significant decreases in floc size consequently gave rise to apparent decrease in fluxes. Another point that should be paid attention to was that the floc sizes after regrowth for PACl-PD and PD-PACl were similar, whereas PACl-PD led to flocs with larger $D_{f}$, and thus resulted in more severe flux decline than PD-PACl.

\subsection{Resistance analysis}

Resistance analyses were conducted to explore the membrane fouling mechanisms according to the procedure and equations expressed in Section 2.4. Membrane resistance $\left(R_{m}\right)$, cake resistance $\left(R_{c}\right)$, adsorption resistance $\left(R_{a}\right)$ and pore blocking resistance $\left(R_{p}\right)$ for different coagulation systems with and without breaking stages were plotted percentage-relative to the total resistance and the results were demonstrated in Fig. 7(a) and (b), respectively. It was observed that resistances caused by pore blocking were close to zero for all the tests in the present study and consequently, only $R_{a}, R_{c}$ and $R_{m}$ were depicted in the figures. Referring to Fig. 7(a), it was obvious that for C-UF processes without breakage stage, suspensions coagulated by alum gave rise to smaller $R_{a}$ and $R_{c}$ relative to the total resistance (12\% and 34\%) when compared with those by $\mathrm{PACl}$, with the corresponding values of $20 \%$ and $44 \%$, respectively. This could be explained by the larger and more loosely constructed flocs generated by alum than PACl, as shown in Table 2 .

PD aid could considerably change the resistance distributions in the total resistances. $R_{c}$ proportions decreased by various degrees for both alum and PACl with PD addition and clearly, the decreasing was more significant for $\mathrm{PACl}$ than that for alum. That was probably because the aggregate sizes in $\mathrm{PACl}$ coagulation systems could be improved more markedly by PD aid (Fig. 4). Since the added PD was proved to be conducive to the increase of floc $D_{f}$, coagulation systems with PD aid were

Table 2

Floc properties $\left(d_{50}, S_{f}, R_{f}\right.$ and $\left.D_{f}\right)$ formed in coagulations with breakage and re-growth stages by alum and PACl coagulants with and without PD aids.

\begin{tabular}{|c|c|c|c|c|c|c|c|}
\hline & & \multicolumn{6}{|c|}{ Coagulant } \\
\hline & & Alum & Alum-PD & PD-alum & $\mathrm{PACl}$ & PACl-PD & PD-PACl \\
\hline \multirow{3}{*}{$\begin{array}{c}\text { Floc size } \\
\qquad(\mu \mathrm{m})\end{array}$} & $d_{1}$ & 375.77 & 382.22 & 406.47 & 331.774 & 363.46 & 395.24 \\
\hline & $d_{2}$ & 105.36 & 117.96 & 110.37 & 110.49 & 114.36 & 117.59 \\
\hline & $d_{3}$ & 140.46 & 182.77 & 175.39 & 150.48 & 193.76 & 191.44 \\
\hline$S_{f}$ & & 28.04 & 30.86 & 27.15 & 33.30 & 31.47 & 29.75 \\
\hline$R_{f}$ & & 12.98 & 24.52 & 21.96 & 18.08 & 31.87 & 26.60 \\
\hline$D_{f}$ & & 2.04 & 2.38 & 2.18 & 2.27 & 2.42 & 2.32 \\
\hline
\end{tabular}

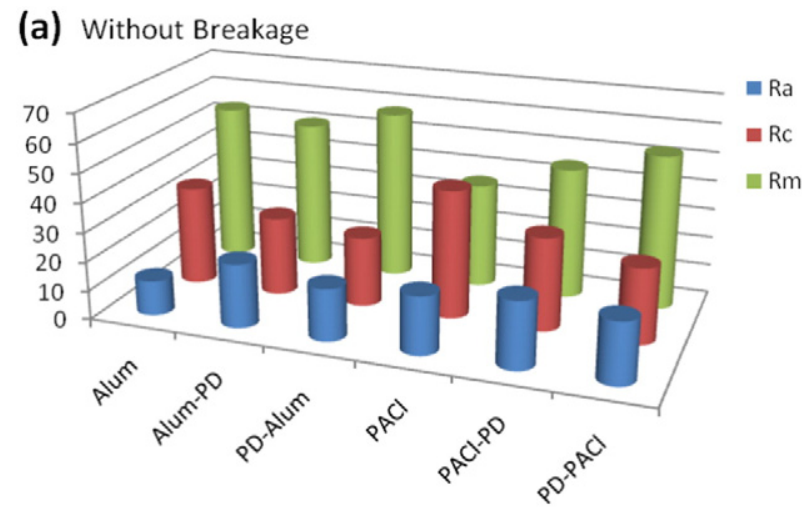

(b) With Breakage and Re-growth

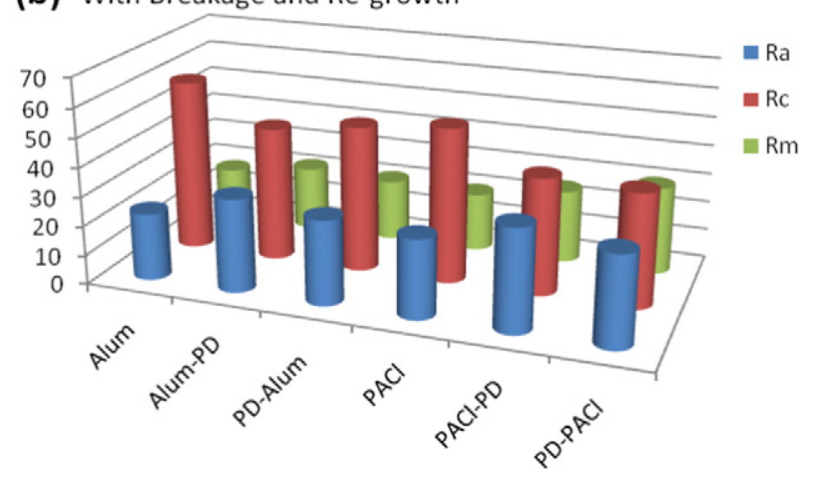

Fig. 7. Resistance analyses of the investigated systems: coagulations by different alumbased and PACl-based coagulants with and without floc breakage and re-growth phases.

supposed to create more denser cake layers. That was, PD aid presented two opposite effects on the $R_{c}$ resistance, a positive effect due to the larger floc sizes and a negative effect due to the more compact flocs. According to the data provided in Fig. 7(a), it could be predicted that floc fractal structure contributed to much less influence on $R_{c}$ than floc size. In contrast, PD addition resulted in evident increases in $R_{a}$ proportions and this could be understood from the point of higher $D_{f}$ of flocs, regardless of their larger sizes. Accordingly, it could be concluded that $R_{a}$ was chiefly affected by floc compact degree instead of floc size. The increase of $D_{f}$ for HA-alum aggregates were more pronounced than that for HA-PACl flocs based on the data in Fig. 4. Therefore, $R_{a}$ increments for alum systems were more obvious. Besides, the data in Fig. 7(a) revealed dosing sequence of chemical agents had distinct influences on the resistance distributions. Alum-PD/PACl-PD resulted in larger $R_{c}$ and $R_{a}$ due to the smaller but dense flocs produced in their coagulation systems; while PD-alum/PD-PACl contributed to larger, unconsolidated aggregates, thereby smaller $R_{c}$ and $R_{a}$ resistance proportions. This was also the reason why PD-alum/PD-PACl contributed to more significant increase in fluxes than alum-PD/PACl-PD as present in Fig. 5.

Visible changes in the resistance distributions could be seen when the preformed aggregates were subjected to breakage and re-growth stages, as demonstrated in Fig. 7(b). $R_{a}$ and $R_{c}$ proportions increased dramatically due to the decreased final floc size and increased $D_{f}$ values after floc breakage and re-growth. As revealed in Table 2, PD aid helped increase $R_{f}$ but had no positive effect on $S_{f}$. The overall effect of PD on floc size, as listed in Table 2, was positive, with larger final floc sizes than those generated in the systems without PD aids. That was the reason why coagulation suspensions with PD resulted in less $R_{c}$ proportions after breakage and re-growth phases, for both alum and $\mathrm{PACl}$ cases. Comparatively, PD aid contributed to flocs with larger $D_{f}$ values, thereby no benefit to the alleviation of $R_{a}$ increments as proved in the present study. 


\section{Conclusions}

The impacts of PD aid on HA removals using C-UF hybrid processes with alum and $\mathrm{PACl}$ coagulants were comprehensively investigated in this study. The key conclusions are as follows:

(1) PD aid with high charge neutralization could essentially increase the HA removals by C-UF hybrid processes at low aluminum doses $(1-3 \mathrm{mg} / \mathrm{L})$ and the synergistic effect of alum and PD was more significant than that of $\mathrm{PACl}$ and $\mathrm{PD}$.

(2) PD aid could improve floc sizes and compact degrees, which had opposite influences on the subsequent UF process. Floc size was proved to play a more significant effect on UF than the compact degree and PD dosing before alum/PACl led to obviously higher fluxes.

(3) Enhanced shear involved in the coagulation process resulted in flocs with smaller sizes but larger $D_{f}$ and thus, apparent flux reductions. When exposed to high shears, alum-PD/PACl-PD contributed to the largest final floc sizes and could alleviate the flux reduction effectively; while the fluxes for PD-alum/PD-PACl system exhibited the most significant reduction due to the poor strength of flocs.

(4) $R_{c}$ resistance was mainly based on floc size, while $R_{a}$ resistance was chiefly affected by floc $D_{f}$. As a result, PD-alum/PD-PACl contributed to larger, unconsolidated aggregates, thereby smaller $R_{c}$ and $R_{a}$ resistance proportions than other coagulants. When the coagulation units were exposed to increased shears, PD aid could alleviate the increments of $R_{c}$.

\section{Acknowledgments}

The research was supported by the National Natural Sciences Foundation of China (Nos. 21377071, 21175057, 21075052), the Natural Sciences Research Foundation of Jinan University (No. XKY 1217), the Natural Science Foundation of Shandong Province (ZR2010ZR063) and the Special Taishan Scholar Professorship of Shandong Province and UJN (No. ts 20130937). The kind suggestions from the anonymous reviewers are greatly acknowledged.

\section{References}

[1] M. Luo, Z. Wang, Complex fouling and cleaning-in-place of a reverse osmosis desalination system, Desalination 141 (2001) 15-22.

[2] Y. Kaiya, Y. Itoh, S. Takizawa, K. Fujita, T. Tagawa, Analysis of organic matter causing membrane fouling in drinking water treatment, Water Sci. Technol. 41 (2000) 9-67.

[3] J. Cho, G. Amy, J. Pelligrino, Y. Yoon, Characterization of clean and natural organic matter fouled NF and UF membranes, and foulants characterization, Desalination 118 (1998) 101-108.

[4] W. Yuan, A.L. Zydney, Humic acid fouling during ultrafiltration, Environ. Sci. Technol. 34 (2000) 5043-5050.

[5] A.R. Costa, M.N. Pinho, Effect of membrane pore size and solution chemistry on the ultrafiltration of humic substances solutions, J. Membr. Sci. 255 (2005) 49-56.

[6] M.R. Wiesner, J.M. Laine, Coagulation and membrane separation, in: J. Mallevialle, P.E. Odendaal, M.R. Wiesner (Eds.), Water Treatment Membrane Processes, American Water Works Association Research Foundation, McGraw-Hill, New York, 1996, pp. 16.1-16.12 (Chapter 16).

[7] S.J. Judd, P. Hillis, Optimisation of combined coagulation and microfiltration for water treatment, Water Res. 35 (2001) 2895-2904.
[8] W.Y. Xu, B.Y. Gao, R.R. Mao, Q.Y. Yue, Influence of floc size and structure on membrane fouling in coagulation-ultrafiltration hybrid process - the role of $\mathrm{Al}_{13}$ species, J. Hazard. Mater. 193 (2011) 249-256.

[9] K.J. Hwang, H.C. Liu, Cross-flow microfiltration of aggregated submicron particles, J. Membr. Sci. 201 (2002) 137-148.

[10] M.H. Cho, C.H. Lee, S. Lee, Influence of floc structure on membrane permeability in the coagulation-MF process, Water Sci. Technol. 51 (2005) 143-150.

[11] E. Barbot, S. Moustier, J.Y. Bottero, P. Moulin, Coagulation and ultrafiltration: understanding of the key parameters of the hybrid process, J. Membr. Sci. 325 (2008) 520-527.

[12] W.Y. Xu, B.Y. Gao, Effect of shear conditions on floc properties and membrane fouling in coagulation/ultrafiltration hybrid process-the significance of $\mathrm{Al}_{\mathrm{b}}$ species, J. Membr. Sci. 321 (2008) 132-138.

[13] E.E. Chang, P.C. Chaing, S.H. Chao, C.H. Liang, Effects of polydiallyldimethyl ammonium chloride coagulant on formation of chlorinated by products in drinking water, Chemosphere 39 (1999) 1333-1346.

[14] J.C. Wei, B.Y. Gao, Q.Y. Yue, Y. Wang, W.W. Li, X.B. Zhu, Comparison of coagulation behavior and floc structure characteristic of different polyferric-cationic polymer dual-coagulants in humic acid solution, Water Res. 43 (2009) 724-732.

[15] J.F. Lee, P.M. Liao, D.H. Tseng, P.T. Wen, Behaviour of organic polymers in drinking water purification, Chemosphere 37 (1998) 1045-1061.

[16] B.Y. Gao, Z.J. Zhang, J.W. Ma, X.Y. Cao, Solid-solid mixed method to prepare polyaluminum chloride, Environ. Chem. 24 (2005) 569-572 (in Chinese).

[17] H.Z. Zhao, Z.K. Luan, Y.B. Su, S.G. Wang, Purification and characterization of $\mathrm{Al}_{13}$ species, Chem. J. Chin. Univ. 23 (2002) 751-755 (in Chinese).

[18] Y. Wang, B.Y. Gao, X.M. Xu, W.Y. Xu, G.Y. Xu, Characterization of floc size, strength and structure in various aluminum coagulants treatment, J. Colloid Interface Sci. 332 (2009) 354-359.

[19] R.J. Francois, Strength of aluminum hydroxide flocs, Water Res. 21 (1987) 1023-1030.

[20] M.A. Yukselen, J. Gregory, The reversibility of floc breakage, Int. J. Miner. Process. 73 (2004) 251-259

[21] R.M. Wu, D.J. Lee, T.D. Waite, J. Guan, Multilevel structure of sludge flocs, J. Colloid Interface Sci. 252 (2002) 383-392.

[22] G.C. Bushell, Y.D. Yan, D. Woodfield, J. Raper, R. Amal, On techniques for the measurement of the mass fractal dimension of aggregates, Adv. Colloid Interface Sci. 95 (2002) 1-50.

[23] K.H. Choo, C.H. Lee, Membrane fouling mechanisms in the membrane-coupled anaerobic bioreactor, Water Res. 30 (1996) 1771-1780.

[24] B. Bolto, D. Dixon, R. Eldridge, S. King, Cationic polymer and clay or metal oxide combinations for natural organic matter removal, Water Res. 35 (2001) 2669-2676.

[25] S.K. Kam, J. Gregory, The interaction of humic substances with cationic polyelectrolytes, Water Res. 35 (2001) 3557-3566.

[26] E. Pefferkorn, Clay and oxide destabilization induced by mixed alum/macromolecular flocculation aids, Adv. Colloid Interface Sci. 120 (2006) 33-45.

[27] C.A. Biggs, P.A. Lant, Activated sludge flocculation: on-line determination of floc size and the effect of shear, Water Res. 34 (2000) 2542-2550.

[28] J.J. Ducoste, M.M. Clark, The influence of tank size and impeller geometry on turbulent flocculation: I, Exp. Environ. Eng. Sci. 15 (1998) 215-224.

[29] W.P. Cheng, F.H. Chi, A study of coagulation mechanisms of polyferric sulfate reacting with humic acid using a fluorescence-quenching method, Water Res. 36 (2002) 4583-4591.

[30] A.W. Zularisam, A.F. Ismail, M.R. Salim, Mimi Sakinah, T. Matsuura, Application of coagulation-ultrafiltration hybrid process for drinking water treatment: optimization of operating conditions using experimental design, Sep. Purif. Technol. 65 (2009) 193-210.

[31] K.Y. Choi, B.A. Dempsey, In-line coagulation with low-pressure membrane filtration, Water Res. 38 (2004) 4271-4281.

[32] K. Listiarini, D.D. Sun, J.O. Leckie, Organic fouling of nanofiltration membranes: evaluating the effects of humic acid, calcium, alum coagulant and their combinations on the specific cake resistance, J. Membr. Sci. 332 (2009) 56-62.

[33] J. Wang, J. Guan, S.R. Santiwong, T.D. Waite, Characterization of floc size and structure under different monomer and polymer coagulants on microfiltration membrane fouling, J. Membr. Sci. 321 (2008) 132-138.

[34] N.A. Ochoa, M. Masuelli, J. Marchese, Development of charged ion exchange resinpolymer ultrafiltration membranes to reduce organic fouling, J. Membr. Sci. 278 (2006) 457-463.

[35] M.A. Masuelli, M. Grasselli, J. Marchese, N.A. Ochoa, Preparation, structural and functional characterization of modified porous PVDF membranes by $\gamma$-irradiation, J. Membr. Sci. 389 (2012) 91-98. 